\title{
Inclusion of an Autistic Child in Kindergarten Facility: A Case Study
}

\author{
Ibrahim Al-Qaryouti*, Ghazwa Nachabe \& Tamara Leeder \\ Sultan Qaboos University, Sultanate of Oman
}

Received: 29/5/2017

Accepted: 10/9/2017

\begin{abstract}
This study aimed to investigate the effects of inclusion of an autistic child, at entrance age of four years and seven months, into the Child Care Center of the Sultan Qaboos University. The study was designed to specifically answer: (1) Which domains of the ASDA scale did 'Ahmad' show notable improvement? (2) Which areas of the academic program did 'Ahmad' show notable improvement? The program at the Center is a bilingual mainstream program in Arabic and English. It is a highly structured and individualized program which covers all of the developmental domains. It caters for two groups of mixed age children from a variety of ethnic backgrounds. The study used the Arabic Scale for Detecting Autism ASDA (Al Qaryouti \& Ababneh, 2006) along with an entrance test and parent interview. The result of this assessment indicated that the subject of this study had autism. After six months, a further application of the scale showed that significant improvement had occurred, particularly in the communication and social interaction domains. Concurrently, the subject made marked progress in his academic studies, notably in the areas of math and language. A further application of the scale a year after the second indicated that the lack of severity of symptoms no longer warranted the autistic label. Inclusion of autistic children in a normal setting can have a positive impact on both social behavior and academic skills, if a well-structured program and a controlled learning environment in the setting of adequately training teachersis applied.
\end{abstract}

Keywords: Autistic, kindergarten, case study, inclusion.

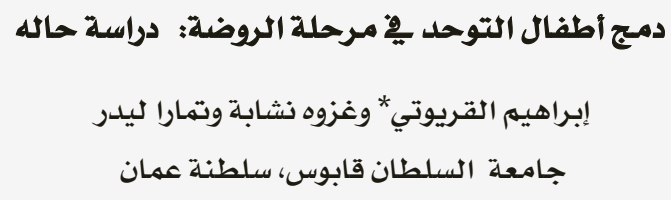

مستخلص: هدفت الدراسة إلى التعرف على الآثار المترتبة على إدماج طفل ِّْ الرابعة من العهر، يعاني من حالة التوحد بِّ2 مركز رعاية

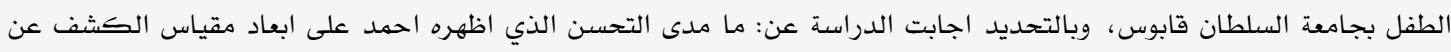

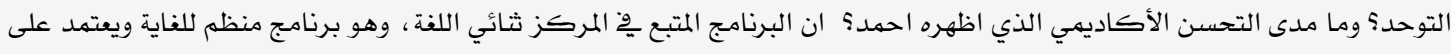

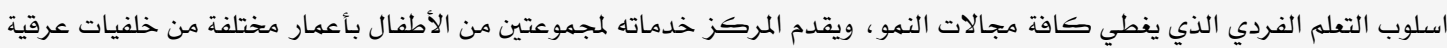

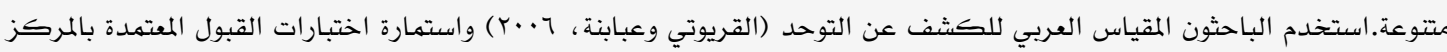

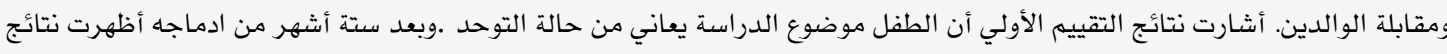

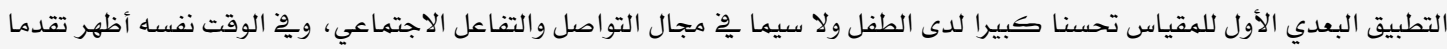

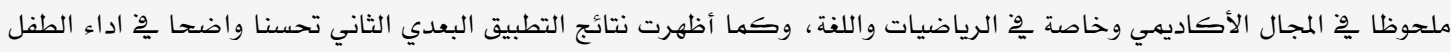

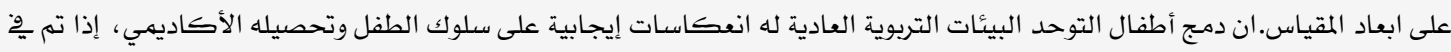

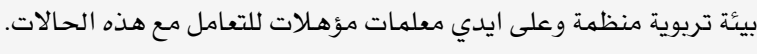
الكلمات المفتاحية: التوحد ، رياض الأطفال، دراسة حالة، الدمج ·

*ibrahim@squ.edu.om 
Autism is a complex neurological disorder that affects the functioning of the brain. It is a pervasive developmental disorder which is characterized by impairment in communication, both verbal and nonverbal, and deficient social interaction, causing significant functional impairment and having an adverse effect on the child's educational performance. (U.S. Department of Education, 2006, p. 35). Children with autism display a restricted repertoire of activities and interests and often engage in repetitive and stereotypical patterns of behavior (American Psychiatric Association, 1994). Those with autism have difficulty adapting to new situations (Ministry of Education, 2000) and have trouble understanding the feelings of others (Griffin Roberts, 2008). Some features of autistic behavior that are easily recognizable and indicative of a need for further investigation when observed in a child are the following:

- Inattention

- $\quad$ Lack of eye contact

- Dislike of physical touch

- $\quad$ Lack of social skills

- Resistance to change

- Hand flapping, spinning or rocking or walking on toes

- Attachment to objects

- Delayed, or lack of, appropriate language development

- Stereotypical language usage or simple repetition of phrases with no apparent meaning.

According to the Diagnostic and Statistical Manual of Mental Disorders (DSM-5), the following diagnostic criteria are indicative of the presence of autism spectrum disorder in an individual.

A. Persistent deficits in social communication and social interaction across multiple contexts, as manifested by the following, currently or by history (examples are illustrative, not exhaustive, see text):

1. Deficits in social-emotional reciprocity, ranging, for example, from abnormal social approach and failure of normal backand-forth conversation; to reduced sharing of interests, emotions, or affect; to failure to initiate or respond to social interactions.

2. Deficits in nonverbal communicative behaviors used for social interaction, ranging, for example, from poorly integrated verbal and nonverbal communication; to abnormalities in eye contact and body language or deficits in understanding and use of gestures; to a total lack of facial expressions and nonverbal communication.

3. Deficits in developing, maintaining, and understanding relationships, ranging, for example, from difficulties adjusting behavior to suit various social contexts; to difficulties in sharing imaginative play or in making friends; to absence of interest in peers.

B. Restricted, repetitive patterns of behavior, interests, or activities, as manifested by at least two of the following, currently or by history (examples are illustrative, not exhaustive; see text):

1. Stereotyped or repetitive motor movements, use of objects, or speech (e.g., simple motor stereotypies, lining up toys or flipping objects, echolalia, idiosyncratic phrases).

2. Insistence on sameness, inflexible adherence to routines, or ritualized patterns or verbal nonverbal behavior (e.g., extreme distress at small changes, difficulties with transitions, rigid thinking patterns, greeting rituals, need to take same route or eat food every day).

3. Highly restricted, fixated interests that are abnormal in intensity or focus (e.g., strong attachment to or preoccupation with unusual objects, excessively circumscribed or perseverative interest).

4. Hyper- or hyperactivity to sensory input or unusual interests in sensory aspects of the environment (e.g., apparent indifference to pain/temperature, adverse response to specific sounds or textures, excessive smelling or touching of objects, visual fascination with lights or movement).

C. Symptoms must be present in the early developmental period (but may not become fully manifest until social demands exceed limited capacities, or may be masked by learned strategies in later life). 
D. Symptoms cause clinically significant impairment in social, occupational, or other important areas of current functioning.

E. These disturbances are not better explained by intellectual disability (intellectual developmental disorder) or global developmental delay. Intellectual disability and autism spectrum disorder frequently co-occur; to make comorbid diagnoses of autism spectrum disorder and intellectual disability, social communication should be below that expected for general developmental level. (Autism Speaks, 2016). All of these factors have a direct impact on the type of learning environment best suited to the autistic child and have serious repercussions for educators wishing to provide an inclusive educational setting for children with autism within the mainstream classroom.

Autism is considered a spectrum of disorders, and while the above-mentioned criteria and characteristics are indicative of autism, every autistic child is different and will display varying degrees of severity of impairment in the various categories. This fact, coupled with the fact that children with autism often also suffer from other related disorders and degrees of mental retardation, means that each autistic child is different and must be catered for on an individual. (Ministry of Education, 2000). That said, there are certain commonalities that exist, and strategies that the mainstream teacher of the autistic child may utilize in order to provide a learning environment that benefits both the autistic child and his or her classroom peers.

Autistic children are also often referred to as 'high functioning' or 'low functioning;' high functioning being those autistic children who have a normal level of intelligence and low functioning being those children with autism who also have some level of intellectual disability (Ministry of Education, 2000). It is most often the high functioning autistic child that is able to be successfully included within the mainstream educational framework. It is a policy of several countries, including the United States of America (Griffin Roberts, 2008), for a child to be educated in the least restrictive environment that they can possibly be accommodated in. This is a challenge for mainstream teachers who may not have re- ceived any specific training on strategies to employ with the autistic child.

\section{Education Programs for the Autistic Child}

In programs developed for use in segregated special needs facilities, intensive behavioral techniques are employed to teach specific skills. These skills may be life skills, social skills or academic skills. Most programs employ Intensive Behavioral Intervention (IBI), based upon Applied Behavioral Analysis principles (ABA). Programs are individualized and usually use one to one teaching for a minimum of twenty hours per week, although small group work may also be utilized. Student cooperation is maintained using positive outcomes and rewards. These programs are highly structured and aim to provide the student with basic skills that will promote adult independence by developing and maintaining useful and adaptive behaviors and eradicating inappropriate or dysfunctional behaviors. (Parsons et al., 2011)

Discrete Trial Training (DTT) is one particularly highly utilized teaching technique which comes under the umbrella of IBI. This technique involves breaking down tasks into multiple steps which are then taught gradually and repeatedly until mastery is achieved.

Consensus exists on the need for early assessment and intervention in order to recognize the specific needs of each child and to improve his or her emotional, educational, social and cognitive development. There is no conclusive evidence to show that any one particular type of intervention is best, although early intervention has proven to be effective. Disagreement lies in how best to provide for the needs of the autistic child; in special needs facilities or within the mainstream learning environment. More research is needed in this area due to the lack of empirical data to support one view over the other. (Humphrey \& Symes, 2011; Parsons et al., 2011)

\section{Educational Program at the Child Care Cen- ter, Sultan Qaboos University}

The early childhood program at Sultan Qaboos University is based upon a combination of well recognized educational philosophies. It utilizes aspects of Montessori, Marie Clay and Vigotsky. The rubrics for the program covers the following learning areas: 


\section{Language}

Oral communication, reading, writing and understanding media materials

\section{Mathematics}

Number sense and numeration, measurement, spatial sense and geometry, patterning and data management and probability.

\section{Science and Technology}

Biology and exploration and experimentation.

The arts: Visual arts, music, drama and movement

Creative activity and response to artwork.

\section{Personal and Social Development}

Self-Awareness and self-reliance, health and physical activity, social relationships and awareness of surroundings

\section{Islamic Studies}

Aqeedah and Quran and Islamic behaviour (Al-Qaryouti, Nachabe, Leeder \& Hathway, 2017).

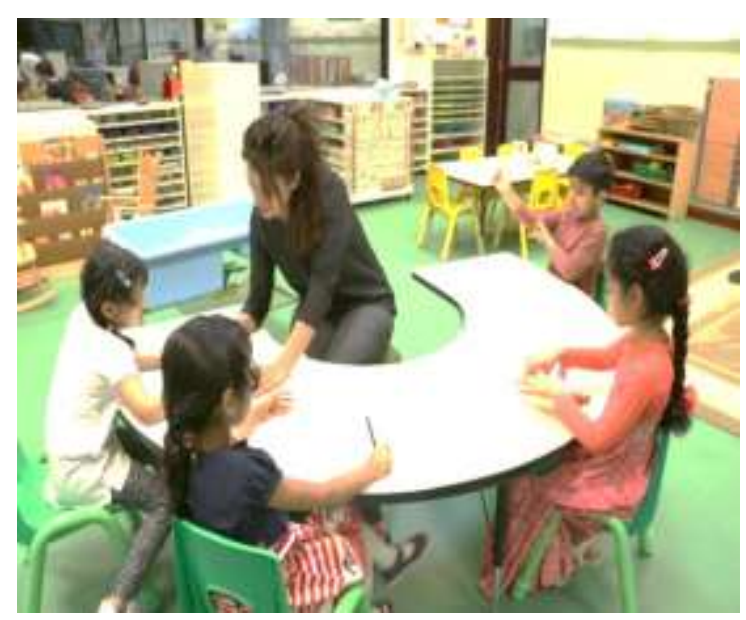

Figure 1: Teacher To Student Ratio

Two multi-aged groups of sixteen children spend two and a half to three hours each in two mirrored educational settings; one in English and one in Arabic. The programs in both classes are parallel, with the same topic covered in each class on any given day during the mat session. The program consists of whole group activities which include calendar, story reading, songs and a themed mat session, as well as gym, outdoor play and individual activities.Three teachers are present in each classroom, giving a teacher to student ratio of about one to five, Figure 1 shows the teacher to student ratio.

\section{Classroom Environment}

Each classroom is well organized into various learning areas including math, language, social studies, science and art. A blocks area is provided for free play and includes props for imaginative play. A mat area is used for group activity time and appropriately sized tables and chairs are placed throughout each room at which children can complete their own activities.

The classrooms are painted in neutral colors and the walls are not decorated, thus reducing visual stimuli and unnecessary distractions that can cause havoc to the autistic child. Because both classes run on the same timetable at the same time there are no noise distractions either (see Figure 2).

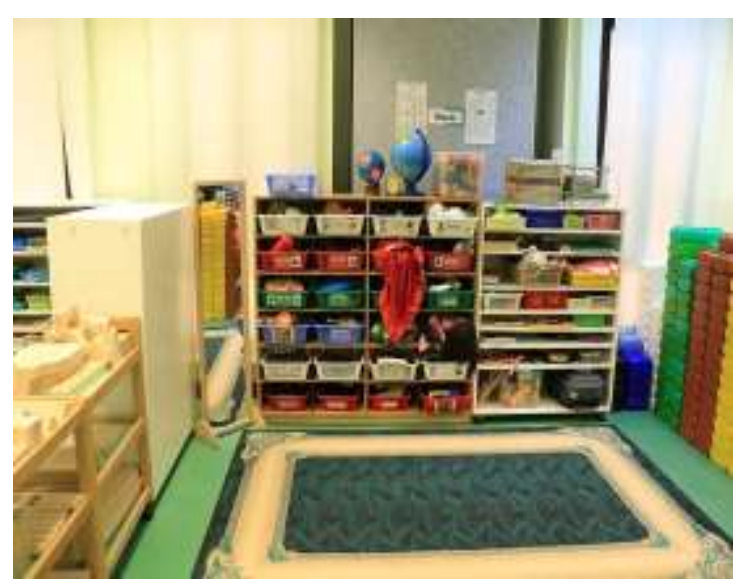

Figure 2: Classroom Environment

\section{Classroom Program}

The program is broken into fortnightly chunks. During each two week period the same topic is presented during group activity time; the same gym skills are taught and the same song and story are read. Skills are taught and built upon each consecutive day.

The daily timetable is consistently followed and is the same for both sessions that the child attends, both in the Arabic classroom and the English classroom. This creates a predictability that is very comforting for the autistic child.

Group sessions are only ten minutes in length. Interestingly it has been found that short periods of structured learning are as or more effective than longer sessions as asserted by Colozzi, Ward, and Crotty (Parsons et al., 2011). 
All group lessons, as well as the song and story, incorporate the use of visual and/or concrete materials to facilitate greater understanding. (Moosa et al., 2013). This is particularly helpful to the autistic child who very often takes a visual approach to learning (Teaching Students with Autism, 2000).

The major chunk of each session (approximately one hour) is spent on individual activities. During each individual activity session, the children are asked to complete activities from the various learning areas, appropriate to their level or skill or according to their interests. They also have the opportunity to play in the blocks area, to read and to use the computer or the water table during this time. Each child also spends ten to fifteen minutes at the snack table in quiet conversation with his or her friends. Vocabulary or skills related to activities that are not yet mastered are noted in each child's notebook, which is taken home at the end of each day. These simple skills are revised at home. A study by Koegel et al (Parsons et al., 2008) suggests that completing simple related tasks at home or at school, prior to the targeted learning creates greater success. Children most often return to school the following day able to complete the targeted activity and being able to progress to the next level. Individual activities use concrete and semi concrete materials to learn skills and concepts. Each activity has well defined steps that must be followed. This is particularly helpful to the autistic child who benefits from small step instructions and a hands-on approach to learning. (Griffith Roberts, 2008).

When a child masters an activity, they are congratulated for 'closing their triangle' and introduced to the next activity in the learning sequence. This is meaningful reinforcement and a natural consequence of their success.

Because all activities are individualized, the child is always working at an appropriate level (see Figure 3). This reduces the frustration for the autistic child who may lack the communication skills to express their frustration appropriately. Individualized instruction also means that the child can work at their own pace. Autistic children often have a delayed response to verbal instructions and may take longer to process information and respond than the typically developing child. (Teaching Students with Autism, 2000).
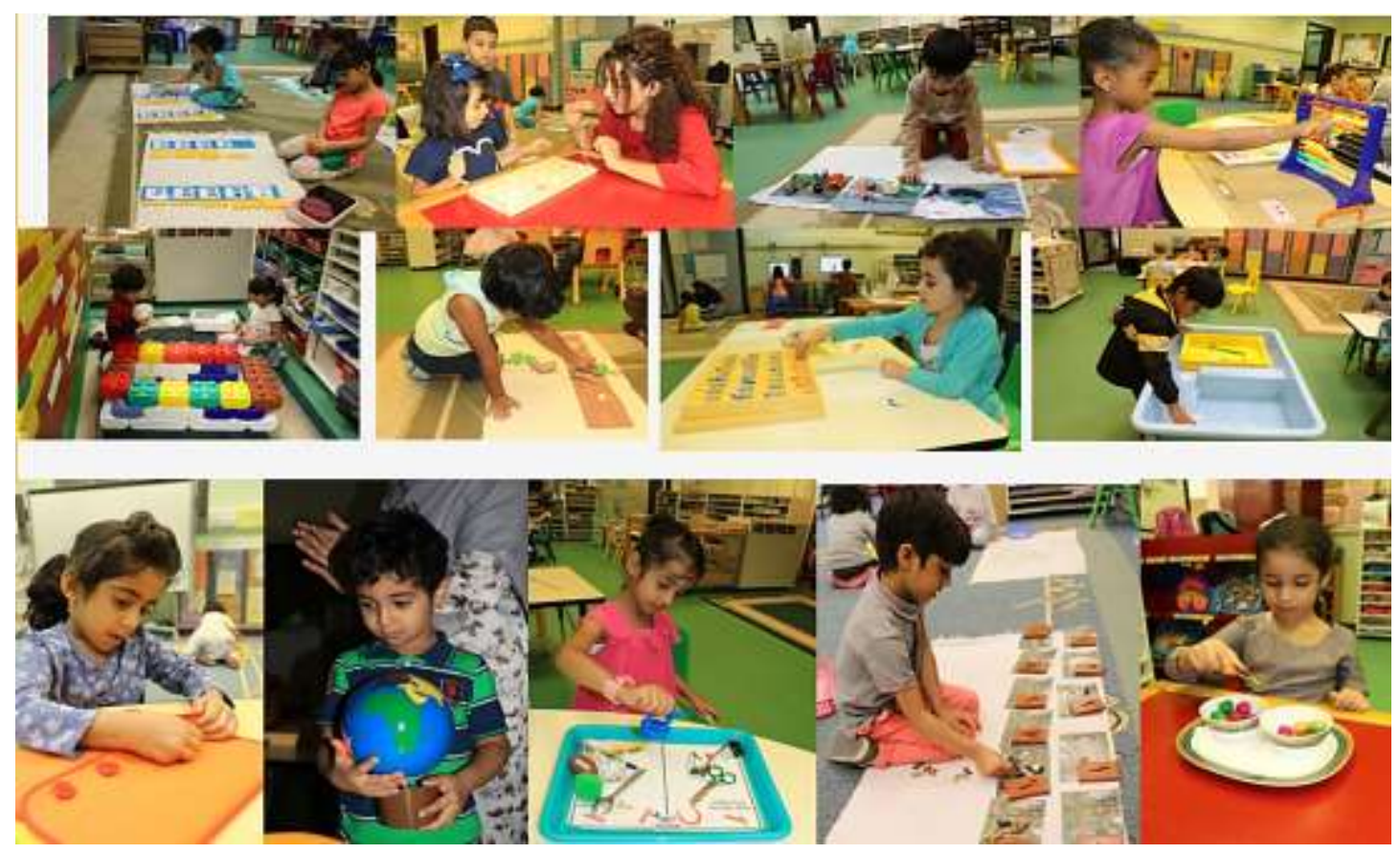

Figure 3: Individual activity 
Given that individualized nature of the learning program, ample opportunity exists for the development of talent within any one sphere of the curriculum spectrum. Autistic children often show remarkable talent or honed interest in abstract skills such as those relating to music, math or decoding. The child has the opportunity to make choices about which learning area they would like to work in and the type of activity they would like to undertake. This is of particular importance to the autistic child who is not always able to make their wants and needs known.

Opportunities for peer communication take place at the snack table, in the blocks area and during outdoor play. Social skills and conversation are explicitly taught as part of the program. This is of importance to the autistic child who may not simply 'pick up' the correct way to respond in various social situations (Daily, 2009). The children are taught to independently and appropriately deal with problems that arise between themselves by voicing their needs clearly to their peers, or their teachers if the situation requires that. Physical or otherwise inappropriate responses are not accepted.

Similarly, to the Nest program discussed earlier, the program at the Child Care Center is highly structured to provide predictability and clear expectations. Just like the program trialed in New York, the environment is clutter free and offers few distractions. Visual aids in the form of objects and materials accompany all activities.

\section{Aims of the Study}

The main aim of the current case study was to investigate the effects of inclusion an autistic child into a normal kindergarten setting. Observations were made of his behavioral and educational achievement. This article aimed to answer the following questions:

1. In which domains of the ASDA scale did 'Ahmad' show notable improvement?

2. In which areas of the academic program did 'Ahmad' show notable improvement?

\section{Inclusion in Classroom Setting}

Despite the fact that inconclusive data exists to support inclusion, the perceived benefits of inclusion are numerous, for both the autistic child and his or her peers. Inclusion is also the preferred option of parents, who overall, de- sire their children to be in the most inclusive environment possible (Patten Koenig et al., 2014).

Generally, it is the academically capable autistic child who is eligible for inclusion. Despite this, they may present other behaviors which make it difficult for them to adapt to the classroom environment. Often their responses to the sensory environment will be atypical. The child may have difficulty self-regulating his or her behavior and may also experience great difficulty with social engagement. These factors can have a huge impact on their chances of academic success and life opportunities. (Leach \& Duffy, 2009).

Social adaption is vital to the future success of the autistic child and the mainstream setting provides the opportunity for the child to be 'taught' social skills by not only the teacher, but by classroom peers as well. Social skills are also modeled in a way that cannot occur in a segregated setting. Socialization is greater in the child directed setting, whether it be in small groups or one to one. The inclusion sitting creates ample opportunities for this and for personal growth and acceptance to occur. However, social skills are most often not 'picked up' by autistic children, and need to be specifically taught through social competence training based upon cognitive behavioral therapy or 'social stories.' While these strategies are directed at fulfilling the specific needs of the autistic child, all children can benefit from direct teaching of social skills. (Parsons et al., 2011).

Similarly, there is some evidence to suggest that a child centered, rather than teacher led approach, is more effective in facilitating play. Typically developing peers can also be paired with the autistic child, and encouraged to follow the lead of the autistic child. This type of less structured and more naturalistic approach has shown promising signs of improving the social interaction of autistic children. (Parsons et al., 2011)

Inclusion of an autistic child teaches his or her mainstream peers the importance of the acceptance of every individual. It also provides them with appropriate skills in dealing with difference. (Humphrey \& Symes; Griffith Roberts, 2008).

Although the autistic child may benefit indirectly from the inclusion environment it is also 
vital that he receives systemic support according to his specific needs. Training parents in the areas of social and communicative interaction is also of paramount importance. (Lindsay, Proulx, Thomson \& Scott, 2013; Parsons et al., 2011).

Many programs of an inclusive nature that currently exist are not based upon any research but rather have developed based upon the experience of practitioners and teachers in the field. (Parsons et al., 2011).

One program that has been trialed in New York public schools is the Autistic Spectrum Disorder (ASD) Nest program. This program provides support and training to teachers, parents and other professionals involved in the care of the autistic child, and provides a link between the school and home. Support is provided to ease the transition from home to school. P.L 99-457 cited the family as the primary learning environment for infants and young children. It stated that a critical need existed for parents and professionals to function in a collaborative fashion (Nuttal, Romero \& Kalesnik, 1992).

Nest classrooms are organized to minimize distractions, provide predictable routines and develop clear expectations. Visual aids are incorporated due to the fact that many ASD children process information visually rather than auditory. Teachers are taught the positive behavior support technique to address impeding behaviors and replace them with appropriate behaviors which serve the same function for the child. It is a proactive technique which aims to render inappropriate behaviors useless (Burack, Root \& Zigler, 1997; Booth \& Ainscow, 2002; Patten Koenig et al., 2014).

These factors are vital to the success of any program aimed at including the autistic child. Parsons et al (2011) conducted an international review of research related to educational provision for autistic children. They concluded that it was necessary to provide a range of different strategies and methodologies to provide for the wide diversity of needs of children with autism. Intensive behavioural techniques were found to be successful in teaching specific skills to some children, however it was noted that success cannot be based only upon academic outcomes. Of vital importance is the acquisition of communicative competency, social understanding, physical and emotional well-being and independence skills.

They also found that many programs were based upon the experience of practitioners in the field, rather than upon research, and that more research is needed to establish what works best for children on the autism spectrum. Patten Koenig et al., (2014) explored the implementation of the Autistic Spectrum Disorder (ASD) Nest program in public schools in New York City. They noted that many children with autism are educated in separate specialized facilities while others are placed in more inclusive environments, but without the support that such a placement necessitates. This often results in problems which lead to these children being moved to increasingly restrictive environments.

Lynch and Irvine (2009) advocate an inclusive model of education for Autistic Spectrum Disorder (ASD) students which is authentic and provides the support required to help all children succeed. Inclusion is not just inclusion, but adjusting the program to cater for individual needs. Their model necessitates that all classrooms include elements that will facilitate success for ASD children. The greatest benefits they see are the opportunity for enhanced personal growth, greater opportunities for social interaction and learning from peers, and acceptance.

Eldar, Talmor, and Wolf-Zukerman (2010) reported that children with autism display greater levels of social interaction when among typical children. They also can be exposed to positive role models and engage as members of the same society that they will eventually share as adults.

\section{Method}

\section{Sample}

Ahmad (not the child's real name) was four years and one month of age. He is an autistic child and subject of this case study.

\section{Instruments}

\section{Entrance test and parent interview}

Entrance testing for the 2014/2015 school year took place in March of 2014. This testing consists of an assessment of the child's ability in English and Arabic as well as their fine and gross motor skills. Anecdotal notes are rec- 
orded regarding the child's general behavior and attentiveness to the tasks performed. A parent interview is also conducted in which the aims of the program are outlined. Further information is collected about the child's habits and behavior in this interview.

\section{The Arab Scale for Detecting Autism}

The Arab Scale for Detecting Autism - ASDA, (Al Qaryouti \& Ababneh, 2006) was administered to make the assessment of autism. This test consists of five domains, communication and social interaction, stereotypical behaviors, self-awareness and awareness of others, sensory-motor disorders and aggressive behavior. The scale showed that the factorial and discriminate validity were significant. The dimensions which extracted accounted for $59.11 \%$ of the total variance; moreover, the discriminant analysis showed that the scale has the power to classify more than $77.2 \%$ of the cases correctly. The reliability coefficient calculated by Cronbach alpha was 0.89, whereas reliability coefficients for the dimensions of the scale ranged between 0.42 and 0.89 . The t-test showed that the differences between performance means of autistics and Normal children were statistically significant.

\section{Study Limitation}

The program applied in only one specialized child center, but not inclusive school. The Entrance test, parent interview and The Arab Scale for Detecting Autism, was used in the study.

\section{Result and Discussion}

\section{Date collection and analysis}

The entrance test and parent interview

At the time of this testing 'Ahmad' (not the child's real name) was four years and one month of age. The assessing teachers were not informed of any suspicion of a learning disorder. They noted that 'Ahmad' was very quiet and did not make any eye contact at all. He did not respond when spoken to. He would only respond when he knew something, otherwise he would remain silent. In both English and Arabic, he had some knowledge of shapes and numbers. He could name some objects but did not show understanding of any verbs presented. He used a left-handed, whole hand grip when writing. He appeared to lack concentration and displayed unclear speech in both languages. He pushed in his chair when he stood up.

During the parent interview the mother informed the teacher that 'Ahmad' would eat the same thing for a week or more, while refusing to eat anything else. He was verbally unresponsive except if a discussion related to numerals and letters of the alphabet. He had been registered in another school the previous year and the teachers had complained constantly about his lack of response and participation and unwillingness to speak. The mother had not been provided with any label for what she was seeing in her child but she had noted that his behaviors were not normal.

The Arab Scale for Detecting Autism Assessment 1

The Arab Scale for Detecting Autism - ASDA, (Al Qaryouti \& Ababneh, 2006) was administered to make the assessment of autism. This test consists of five domains as follows, with the number of items in each domain as indicated in Table 1 below, tallying to a total of sixty-four items. The third column indicates the highest possible score within the domain, while the last indicates the score which 'Ahmad' achieved in each. The data was collected by the researchers, from the child's mother and during the observation of the child in different settings.

Table 1

ASDA Domains and Assessment 1 Scores

\begin{tabular}{llll}
\hline \multicolumn{1}{c}{ Domain } & $\begin{array}{l}\text { Degree of } \\
\text { the lower } \\
\text { boundary }\end{array}$ & $\begin{array}{c}\text { Degree of } \\
\text { the upper } \\
\text { boundary }\end{array}$ & $\begin{array}{c}\text { Score } \\
\text { achieved }\end{array}$ \\
\hline $\begin{array}{l}\text { Communication } \\
\text { and social inter- } \\
\text { action }\end{array}$ & 37 & 111 & 96 \\
$\begin{array}{l}\text { Stereotypical } \\
\text { behaviors }\end{array}$ & 10 & 30 & 13 \\
$\begin{array}{l}\text { Self-awareness } \\
\text { and awareness } \\
\text { of others }\end{array}$ & 10 & 30 & 23 \\
$\begin{array}{l}\text { Sensory-motor } \\
\text { disorders }\end{array}$ & 4 & 12 & 4 \\
$\begin{array}{l}\text { Aggressive } \\
\text { behavior }\end{array}$ & 3 & 9 & 3 \\
Total & 64 & 192 & 139 \\
\hline
\end{tabular}

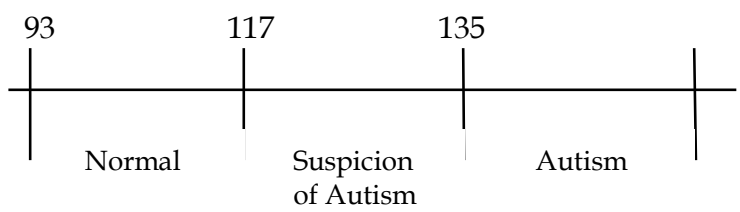

Figure 4: ASDA Scale Grading for Assessment 1 
This test was conducted in September of 2014, when 'Ahmad' had just entered the Child Care Center to begin his studies there. His result indicated a diagnosis of definitive autism. At this time, he was four years and seven months of age. The area of greatest concern, according to these results, was that of communication and social interaction. 'Ahmad' also scored high in self-awareness and awareness of others.

It was noted during 'Ahmad's' first few months at school that he did not express any feelings by way of facial expressions or body language. He did not make eye contact or engage in conversation of any kind with either the teachers or other children. He was unresponsive when questions were asked of him that were not directly related to his learning and had to be taught appropriate social responses. He was fearful of the hand dryer initially and it took a few months of gentle encouragement before he was able to use it comfortably. He was unable to let his needs known and would respond to requests he was unhappy with by simply standing in one place and not responding. If another child annoyed him he would respond by screaming. He was often unwilling to eat his snack and had to be guided through the snack time routines of washing his hands and cleaning his place after eating. He would not initiate any speech. He would only respond, and even then, it was a seldom occurrence and almost always related to his academic activities. He was unable to make choices when presented to him.

The teachers met with 'Ahmad's' mother in early November of 2014. She reported progress in Ahmad's social learning. He had started to use some sentences at home and to play with other children where previously he had always remained beside her. The family had previously not known how Ahmad felt towards them but he had started to express some feelings at home. She also said that if he ever became upset they would show him number toys and he would quickly forget whatever had troubled him.

The teachers reported that 'Ahmad' was unable to make choices when presented by the teacher and that it was necessary to direct him to do his activities and that he would not independently move between his activities or choose an activity to undertake.
A few months into the program 'Ahmad' started to respond with learnt phrases like "I am fine" when asked "How are you?" He also began to actively participate during group sessions by making simple responses to questions about learnt concepts that did not involve anything more than repeating a learnt word or phrase. He would occasionally make a little eye contact and sometimes chose an independent activity in the outdoor area.

Children are required to place their hand on a teacher's shoulder upon completion of their activity so that it can be checked. 'Ahmad' started to do this in February of 2015. He also began to make simple responses to questions like "Have you eaten your snack?" Previously he would not respond.

A further parent-teacher conference took place at the end of February. 'Ahmad's' mother showed the teachers a video of 'Ahmad' at home answering her questions. He was responding with phrases and sentences. She said that previously he was unresponsive and that she had felt that he wasn't able to understand her. His mother expressed concern that 'Ahmad' was unable to defend himself and the teachers discussed ways of teaching 'Ahmad' specific responses that he could use when faced with a problem. She said there had been no improvement in 'Ahmad's' eating habits.

\section{Assessment 2 (Phase 1)}

A further assessment was made in March of 2015, again using the ASDA. The results were as follows:

Table 2

ASDA Assessment 2 Scores

\begin{tabular}{lr}
\multicolumn{1}{c}{ Domain } & $\begin{array}{c}\text { Score } \\
\text { Achieved }\end{array}$ \\
\hline Communication and social interaction & 78 \\
Stereotypical behaviors & 14 \\
Self-awareness and awareness of & 21 \\
others & \\
Sensory motor disorders & 4 \\
Aggressive behavior & 3 \\
Total & 120 \\
\hline
\end{tabular}


Table 3

Comparison of Assessment 1 and Assessment 2 Scores

\begin{tabular}{lcc}
\hline \multicolumn{1}{c}{ Domain } & $\begin{array}{c}\text { Assessment } \\
\text { 1 Results }\end{array}$ & $\begin{array}{c}\text { Assessment } \\
\text { 2 Results }\end{array}$ \\
\hline $\begin{array}{l}\text { Communication } \\
\text { and social interac- } \\
\text { tion }\end{array}$ & 96 & 78 \\
$\begin{array}{l}\text { Stereotypical be- } \\
\text { haviors }\end{array}$ & 13 & 14 \\
$\begin{array}{l}\text { Self-awareness and } \\
\text { awareness of oth- } \\
\text { ers }\end{array}$ & 23 & 21 \\
$\begin{array}{l}\text { Sensory motor } \\
\text { disorders }\end{array}$ & 4 & \\
$\begin{array}{l}\text { Aggressive behav- } \\
\text { ior } \\
\text { Total }\end{array}$ & 3 & 3 \\
\hline
\end{tabular}

This subsequent test indicated a diagnosis of suspicion of autism. 'Ahmad' had made significant progress in the area of communication and social interaction whilst still remaining an area of concern. The score he received in this area was 78, down from 96 in the previous assessment. Although this score indicated that considerable progress had occurred, the score was still far off the baseline score of 37 . Some improvement could also be noted for the area of self-awareness and awareness of others, the score having come down from 23 to 21, the baseline being 10 .

These scores accurately portrayed what was being witnessed of 'Ahmad's' behavior in the classroom. While he was becoming far more responsive and communicative, it was still evident that his awareness of himself or those around him was minimal.

\section{Assessment 3 (Phase 2)}

A final assessment was undertaken in May of 2016, upon completion of 'Ahmad's' two years of pre-schooling at the Child Care Center at the Sultan Qaboos University, in order to ascertain the level of autism that he was exhibiting. This was supplemented by an interview with his mother to gauge her level of satisfaction with the program outcomes.

The results from applying the scale for detecting autism were as follows:

Table 4

ASDA Assessment 3 Scores

\begin{tabular}{lr}
\hline Domain & Score Achieved \\
\hline Communication and social interaction & 62 \\
Stereotype behaviors & 13 \\
Self-awareness and awareness of others & 16 \\
Senso-motor disorders & 4 \\
Aggressive behavior & 3 \\
Total & 98 \\
\hline
\end{tabular}

Table 5

Comparison of ASDA Assessment Scores

\begin{tabular}{lccc}
\hline Domain & $\begin{array}{c}\text { Assessment } \\
\text { 1 Results }\end{array}$ & $\begin{array}{c}\text { Assessment } \\
\text { 2 Results }\end{array}$ & $\begin{array}{c}\text { Assessment } \\
\text { 3 Results }\end{array}$ \\
\hline $\begin{array}{l}\text { Communication } \\
\text { and social in- } \\
\text { teraction }\end{array}$ & 96 & 78 & 62 \\
\hline $\begin{array}{l}\text { Stereotype } \\
\text { behaviors }\end{array}$ & 13 & 14 & 13 \\
\hline $\begin{array}{l}\text { Self-awareness } \\
\text { and awareness } \\
\text { of others }\end{array}$ & 23 & 21 & 16 \\
\hline $\begin{array}{l}\text { Senso-motor } \\
\text { disorders }\end{array}$ & 4 & 4 & 4 \\
\hline $\begin{array}{l}\text { Aggressive } \\
\text { behavior } \\
\text { Total }\end{array}$ & 3 & 3 & 3 \\
\hline
\end{tabular}

The results show a further marked improvement in communication and social skills as well as in the development of self-awareness and awareness of others. The score for communication and social skills made a further leap down from 78 to 62 , the lower boundary being 37. In the initial assessment, 'Ahmad' had scored 96 in this domain, very close to the upper boundary of 111 . The score for selfawareness and awareness of others also fell considerably, from 21 to 16, inching towards the lower boundary of 10 . The areas of stereotype behaviors, senso-motor disorders and aggressive behavior were never of any particular concern, 'Ahmad' having achieved scores within the normal range since the outset of the study. In fact, he achieved the baseline score for senso-motor and aggressive behavior on all three assessments. As was discussed earlier, a diagnosis of autism does not necessitate that a child displays autistic behaviors in all domains (Teaching Students with Autism, 2000).

It was in the social domain that the most improvement was noted. His mother had seen a progressive and marked improvement in his social skills and ability to communicate his needs. This was consistent with the research of Eldar, Talmor, and Wolf-Zukerman (2010), who reported that children with autism display greater levels of social interaction when among typical children. At home, he would talk about the activities he has undertaken, who he played with and any new activities introduced at school. He particularly enjoyed reporting to his father about scores achieved by himself or his sisters while playing racing games on the computer. At school, he made eye contact much more often and initiated simple discussion about himself and his surroundings. (e.g. 'I like circles!) While this be- 
gan as a very occasional incident it became more and more prevalent in his behavior as the year progressed. He began answering questions which required a yes or no answer with confidence. He would ask questions to fulfill his needs, such as asking about the activities that he needed to complete in the classroom, however at times his speech would be unclear or unintelligible.

Although his communication skills were greatly improved his mother reported that he still hesitated to talk to strangers. When extended family members wanted to strike up a conversation with him they had learnt to begin with some talk involving numbers in order to make 'Ahmad' comfortable.

He tutored peers at the request of his teachers. His mother said that he would assist his sister in grade two with her math homework also. He had begun to show some interest in playing interactively with his friends, yet seemed to enjoy engaging in activities alone more often. During his first year of schooling he tended to make activity choices based upon the choices of children he liked, while not actually engaging with them. His mother noted that whilst previously he had simply followed his older sisters in their play outside the house, he had gained confidence and had begun to choose activities independently.

His mother said that he no longer reacted to loud noises like he did with the hand dryer when he first began school. She said that he was showing much more awareness of those around him and would mention if someone was sick or sad.

By the end of the school year 'Ahmad' could often be seen smiling and showing happiness in his face and body language. He started to show some expression of happiness and pride in his achievements early in the school year and ended it with obvious acknowledgement visible in his body language and facial expressions. His mother reported that just prior to the end of the school year he verbally expressed his feelings to her for the first time when she laughed at him and he told her that he felt angry.

Although social skills are taught as part of the program of the Center, a focus was placed on this area of learning in order to benefit 'Ahmad' and all of the children in attendance. Research indicates that autistic children bene- fit from social competence training (Parsons et $a l, 2014)$. This, coupled with the ample opportunities for socialization and personal growth presented by the mainstream classroom, meant that 'Ahmad' had every opportunity to develop in this area. Particular care was taken to utilize the opportunity to reinforce appropriate responses when specific incidents occurred. It was noted that by the end of the school year 'Ahmad' was consistently applying the social skills that he has been taught in the classroom to solve social problems that arose in the classroom environment. $\mathrm{He}$ would defend himself verbally if his learning was disrupted or his rights were not fulfilled. He would complain to the teachers about any situation that he couldn't resolve by himself.

'Ahmad's' mother was still very concerned about his inability to defend himself physically. He would not even raise his hands as a defensive measure if another child tried to hit or push him. It was suggested that 'Ahmad' may benefit from learning specific skills in physical defense, such as karate or tai kwon do.

Both the teachers and his mother had noticed that, when faced with many choices, 'Ahmad' became immobile. When the choice was limited to only a few items he was more able to make a decision. This was noted in his inability to choose an activity in the classroom when given free range and by his mother when given the opportunity to choose a toy from the store.

'Ahmad' had shown a particular consciousness of time. He was completely aware of the classroom program and the time at which different sessions should begin and end. $\mathrm{He}$ would often remind the teacher of how much time she had left to complete a group activity with the children or would tell the teacher that he did not have enough time to complete a particular activity before the individual activity time would come to an end.

An improvement in eating habits had been noted by his mother. He was more willing to try new foods. 'Ahmad's academic progress was amazing. By the end of the school year he was reading and writing in both English and Arabic. He loves shapes and numerals and much of his early writing centered around these themes. With encouragement, he began to write on other topics. His reading was still 
largely phonetic and he relied heavily on decoding as a means of deciphering print, however his understanding and use of picture cues and syntax was improving. In math he engaged in activities using fractions and large numbers. He was able to complete equations in addition, subtraction and multiplication and solve word problems which required the use of any of these. His fine motor skills im- proved greatly. He could use scissors and a ruler competently. He participated in story discussion and could scribe a story to the teacher when provided with a picture. $\mathrm{He}$ was very capable of making story predictions, Figure 5 and Figure 6 show samples of his work in the English class.

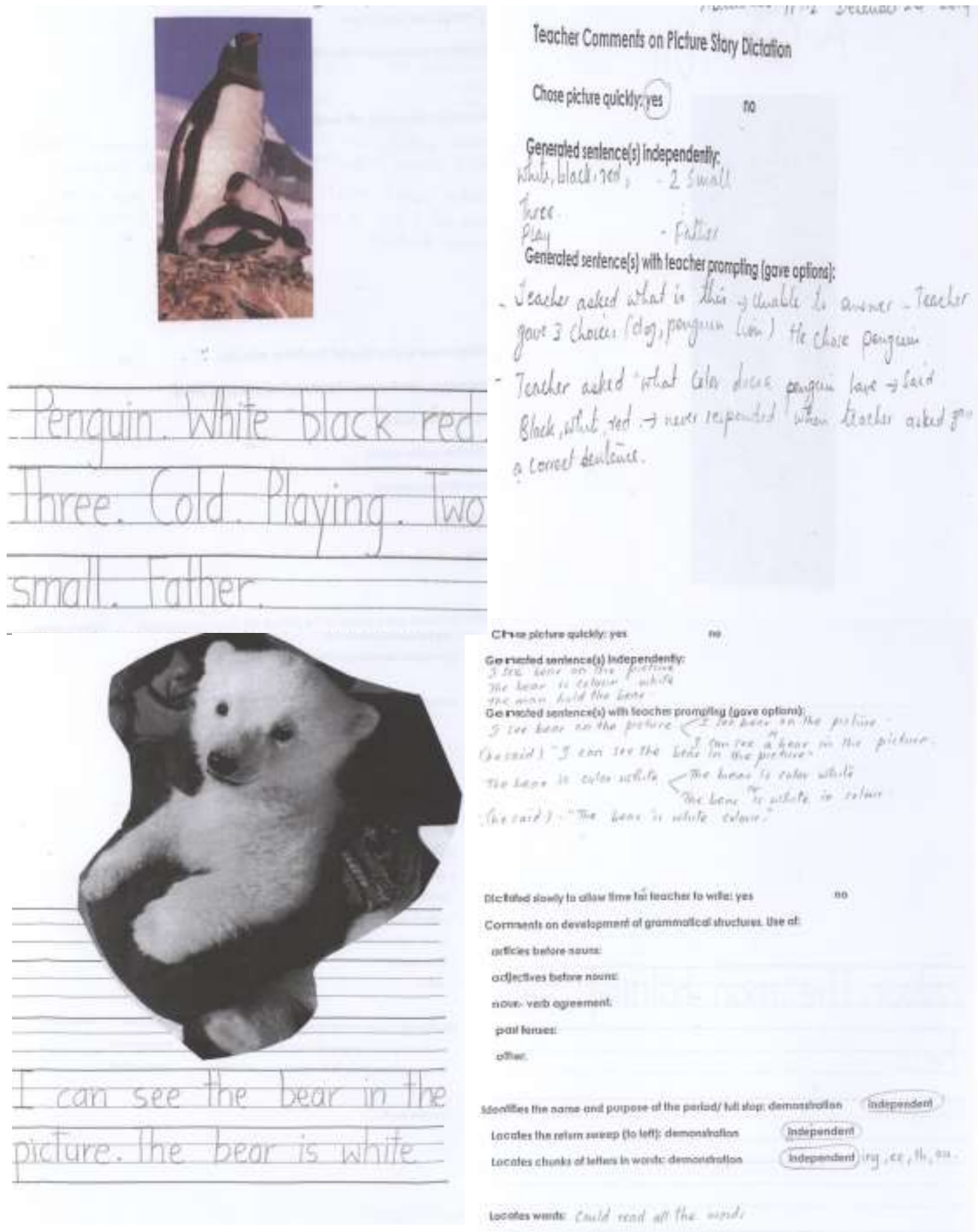

Figure 5: Language Work Sample 


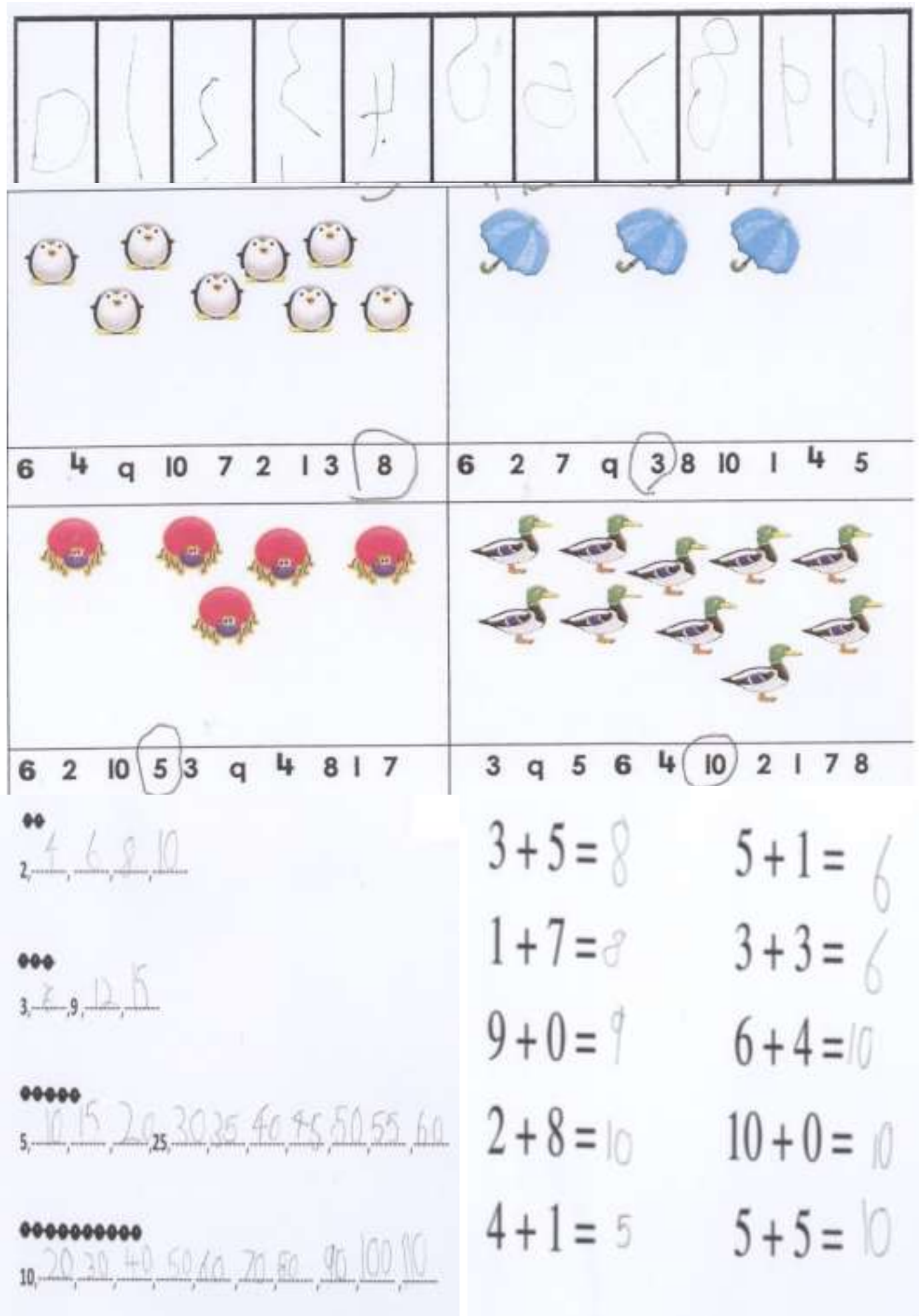

Figure 6: Math Work Sample 


\section{Conclusion}

The program at the Child Care Center is one which caters well for the needs of the mildly autistic child by providing a structured and predictable learning environment. Having professional teachers with solid background in autism along with the daily fixed activities, in the same time and same places with the same teachers in Arabic and English sections, and the use of visual aids in all learning areas is of great benefit and the individualized learning program means that every child can progress at their own rate. The success displayed by 'Ahmad' is indicative of the vital role that can be played by the mainstream school environment in assisting children with autism to overcome some of the behaviors which impede their ability to participate actively in all aspects of their lives. While 'Ahmad' had entered the Child Care Center program clearly autistic, his behavior developed to such a degree that, upon completion, he could be considered outside of the autistic range. Furthermore, the notable decrement in the autistic symptoms that 'Ahmad' initially displayed, achieved through treatment was reflected on his social behavior and communication skills with his peers and teachers, positively affecting his educational improvement in the program, especially in language and math skills.

'Ahmad's' teachers feel confident that with continued support, he will grow and further develop his skills in communication and interacting with others and go on to engage fully in the next school program he enters.

\section{References}

Al-Qaryouti, I., \& Ababneh, E. (2006). Developing Arabic multi-dimensional scale for detecting autism. Jordan Journal for Educational Science, Yarmuk University, 2,2, 7375.

Al-Qaryouti, I; Nachabe, G; Leeder, T; \& Hathway, S (2017) Guide to the Evaluation of Child Development. printed by Sultan Qaboos University Printing Press, Muscat: Sultanate of Oman.

American Psychiatric Association. (1994). Diagnostic and statisticalmanual for mental disorders (4th ed.). Washington, DC: Author.

Autism Speaks (2016) What is Autism. DSM-5 Diagnostic Criteria, retrieved from https//www.autismspeaks.org/what- autism/disgnosis/dsm-5-diagnosticcriteria

Burack, J., Root, R., \& Zigler, E. (1997). Inclusive education for students with autism reviewing ideological, empirical and community considerations. In Handbook of autism and developmental disorders, ed.D.E. Cohen and F. Volkmar,696-807. Chichester: Wiley.

Booth, T. \& Ainscow, M. (2002). Index for inclusion: Developing learning and participation in school. Bristol: Centre for studies in inclusive education.

Daily, M. (2009). Inclusion of Students with Autism Spectrum Disorders. New Horizons: John Hopkins University.

Digest for Educational Statistics, 2005 (NCES 2006-030). Washington, DC:U.S. Government Printing Office.

Eldar, E., Talmor, R., \& Wolf-Zukerman, T. (2010). Successes and difficulties in the individual inclusion of children with Autism Spectrum Disorder (ASD) in the eyes of their coordinators. International Journal of Inclusive Education, 14,1, 97-114.

Griffin Roberts, K. (2008). Modifying the preschool classroom to include children with autism. Unpublished manuscript, George Mason University, Fairfax, Virginia.

Humphrey, N \& Symes, W. (2011) Peer interaction patterns among adolescents with autistic spectrum disorders (ASDs) in mainstream setting. Autism: The International Journal of research and practice, 15, 4, 397-419.

Humphrey, N \& Symes, W. (2013). Inclusive education for pupils with autistic spectrum disorders in secondary mainstream schools: teacher attitudes, experience and knowledge. International Journal of Inclusive Education. 17,1,32-46.

Leach, D., \& Duffy, M. (2009). Supporting students with autism spectrum disorder and the inclusive classroom: Effective training to enhance knowledge of ASD and evidence-based practices. Teacher Education and Special Education: The Journal of the Teacher Education Division of the Council of Exceptional Children,32,2,166-179.

Lynch, S., \& Irvine, A. (2009). Inclusive education and best practice for children with au- 
tism spectrum disorder: an integrated approach. International Journal of Inclusive Education, 13,8, 845-859.

Lindsay, S., Proulx, M., Thomson, N., \& Scott, H. (2013). Educators Challenges of including Children with Autism Spectrum Disorder in Mainstream Classroom. International Journal of Disability, Development and Education,60,4,347-362.

Moosa, S., Hathway, S., Al-Qaryouti, I., AlTawqi, S., \& Nachabe, G. (2013). Child Care Center. Sultan Qaboos University, Muscat, Oman.

Nuttall, E., Romero, I., \& Kalesnik, J. (1992) Assessing and screening preschoolers'. Psychological and educational dimension. Allyn and Bacon, USA.

Parsons, S., Guldberg, K., MacLeod, A., Jones, G., Prunty, A., \& Balfe, T. (2011). International review of the evidence on best practice in educational provision for children on the autism spectrum. European Journal of Special Needs Education, 26,1, 47-63.

Patten Koenig, K., Feldman, J., Siegel, D., Cohen, S., \& Bleiweiss, J. (2014). Issues in implementing a comprehensive intervention for public school children with autism spectrum disorders. Journal of Prevention $\mathcal{E}$ Intervention in the Community, 42,4, 248263.

Ministry of Education (2000). Teaching Students with Autism. Special Programs Branch, British Colombia, Canada: Ministry of Education.

U.S. Department of Education, National Center for Educational Statistics. (2006). 